\title{
LA FILOSOFÍA ANTE EL PROCESO NEOLIBERAL Y LAS REACCIONES DE LOS MOVIMIENTOS SOCIALES EN VENEZUELA (1990-2010)
}

\author{
JOHAN MÉNDEZ REYES \\ Doctor en Ciencias Filosóficas. Magister en Filosofía. Licenciado en Filosofía. Profesor y Jefe del \\ Departamento de Filosofía Latinoamericana de la Escuela de Filosofía. Universidad del Zulia. \\ LINO MORÁN BELTRÁN \\ Doctor en Ciencias Filosóficas. Magister en Filosofía. Licenciado en Filosofía. Profesor del Departamento \\ de Filosofía Latinoamericana de la Escuela de Filosofía. Universidad del Zulia.
}

\section{RESUMEN}

El presente trabajo pretende analizar el papel de la filosofía y de los movimientos sociales en Venezuela durante 1990-2010 ante los desafíos de las políticas neoliberales. La metodología que se utilizará es la hermenéutica para comprender e interpretar los hechos más representativos acontecidos en la Venezuela de finales del siglo XX e inicio del siglo XXI y el papel que ha jugado la filosofía y los distintos movimientos sociales en nuestra sociedad en la era neoliberal. En esta investigación se concluye que los acontecimientos del Caracazo de 1989 y el inicio de la Revolución Bolivariana de 1999, constituyen dos hitos de la historia reciente venezolana que sin lugar a dudas han tenido su impronta en el desarrollo del debate filosófico nacional actual.

Palabras clave: Filosofía, neoliberalismo, movimientos sociales.

\section{ABSTRACT}

The present work tries to analyze the paper of the philosophy and of the social movements in Venezuela during 1990-2010 before the challenges of the neoliberal policies. The methodology that will be in use is the hermeneutics to understand and to interpret the most representative facts happened in the Venezuela of ends of the 20th century and beginning of the 21st century and the paper that has played the philosophy and the different social movements in our company in the neoliberal age. In this investigation one concludes that the events of the Caracazo of 1989 and the beginning of the Revolution Bolivariana of 1999, constitute two milestones of the recent Venezuelan history that no doubt have had his stamp in the development of the philosophical debate current native.

Key words: Philosophy, neoliberalism, social movements. 


\section{LA IRRUPCIÓN DEL PUEBLO ANTE LA IMPLEMENTACIÓN DE POLIITICAS NEOLIBERALES}

Cuando en 1988 Carlos Andrés Pérez llega a la Presidencia por segunda vez, lo hace con el convencimiento que la situación económica del país requiere la adopción de un programa de ajuste económico y de la asistencia de los organismos multilaterales. Los componentes habituales de lo que se llamaba la receta "neoliberal" de esos organismos eran: eliminación de los subsidios de las tarifas de los servicios públicos, sinceración de los precios de productos subsidiados, devaluación de la moneda, privatización de empresa en manos del Estado, reducción del déficit fiscal, disminución de aranceles y apertura de la economía. La fórmula neoliberal que intentó implementar este gobierno produjo lo que la historia contemporánea venezolana ha denominado el Caracazo, hecho que constituye el resurgimiento de las luchas y movilizaciones populares que ponen en evidencia el profundo descontento que anidaba en amplios sectores del pueblo, debido a la no satisfacción de necesidades y aspiraciones prometidas por el sistema democrático.

La crisis económica como consecuencia del agotamiento del modelo de crecimiento basado en el usufructo de la renta petrolera; el agotamiento del sistema político democrático representativo, que no satisfizo las expectativas generadas de la población y que por el contrario deterioró sus condiciones de vida, a la vez que restringía los derechos democráticos más elementales, el derrumbe de las expectativas más favorables que se habían generando en la población a raíz del triunfo electoral de Carlos Andrés Pérez; la carencia de mecanismos legales de protesta para drenar el descontento popular hacia vías institucionales; entre otros aspectos, fueron las causas de este levantamiento popular de febrero de $1989^{1}$.

Este hecho pone de manifiesto otra realidad, con la cual se desvanece la ilusión de armonía que aparentemente caracterizaba la vida democrática venezolana a partir de 1959 tras el derrocamiento de la dictadura de Marcos Pérez Jiménez. El agotamiento del consenso político que sustentó a la modernización rentista populista, la caída constante de la renta petrolera percapital y la crisis del sistema populista de partidos tuvo como uno de sus efectos, además del empobrecimiento colectivo de la sociedad venezolana y la profundización de la brecha social, la generación de un perverso mecanismo de exclusión de grupos sociales, que puede calificarse como de apartheid social, lo cual puso en evidencia durante ese período el eclipse de la función política primordial de lograr el bien común. En cambio, se le dio rienda suelta al ejercicio del poder como forma de garantizar privilegios individuales o grupales y se evitó reconocer los mínimos derechos del colectivo que exigían no solo frenar el empobrecimiento y mejorar la distribución de la riqueza, sino devolverle el futuro a la mayoría al construir un proyecto político donde se les reconociera como seres humanos, culturales y políticos ${ }^{2}$.

1. Cfr. López, Roberto (2009). El protagonismo popular en la historia de Venezuela. Maracaibo: Editorial Escuela de Formación Popular Nuestra América.

2. Cfr. Sosa, Arturo y González, Wilfredo (2008). "Desarrollo histórico del proceso político venezolano del siglo XX” En: Una mirada sobre Venezuela. Caracas: Editorial Centro Gumilla. 
Siendo una expresión de la fuerza potencial que anida en las masas populares, los acontecimientos del 27 de febrero constituyeron un alzamiento que no encajaba en ninguno de los esquemas teóricos tradicionales de los partidos marxistas o socialistas de la izquierda venezolana, y mucho menos, en la interpretación de quienes, desde una perspectiva de pensamiento burgués habíanse apresurado a proclamar el fin de la historia. Este acontecimiento encontró a toda la intelectualidad venezolana sumida en sus textos clásicos de filosofía, los cuales niegan la irrupción espontánea de las masas en la historia. Si bien no se trata de reivindicar la desorganización y la ausencia de plataforma política, en los sucesos del Caracazo, consideramos que constituyó la respuesta espontánea del pueblo a décadas de marginamiento del proceso político venezolano. Las tácticas vanguardistas y mesiánicas desarrolladas por la izquierda intelectual y el tutelaje iluminado por parte de la intelectualidad burguesa se estrellaron ante la realidad de un pueblo alzado que no respetaba liderazgos burocráticos.

Pese a su espontaneidad los sucesos de febrero de 1989 marcan un hito en la historia de Venezuela, y sus repercusiones generaron los alzamientos militares del 4 de febrero y del 27 de noviembre de 1992. La desestabilización del sistema político iniciada con el Caracazo condujo al triunfo electoral de Hugo Rafael Chávez Frías en 1998.

La espontaneidad de la protesta reflejó el debilitamiento del tradicional control que tenían los partidos sobre el movimiento popular, como expresión del desprestigio que las estructu- ras partidistas habían alcanzado en los últimos años. El 2 de febrero de 1999 permitió la irrupción en la política nacional de sectores populares que hasta ese momento, y desde el proceso de conformación de la Venezuela moderna habían estado mediatizados por la acción de los partidos políticos. Aun sin organización y sin propuestas claras, los desposeídos entraron en escena para intentar equilibrar la balanza en la que hasta ahora solo intervenían los poseedores, los dueños del poder económico y político, y sus intelectua$\operatorname{les}^{3}$.

El debilitamiento de los partidos dio paso a un crecimiento organizativo por la base, creándose nuevas organizaciones, nuevos liderazgos, recreando las formas de lucha y formulando propuestas de participación que rompían con el férreo control partidista ejercido durante más de treinta años. En términos generales se podría caracterizar a estos movimientos sociales de la siguiente manera: su enfrentamiento a la injerencia de los partidos en las organizaciones sociales; el liderazgo local o gremial que ejercen en diversos sectores populares; el ejercicio democrático interno sobre la base de criterios autogestionarios, y sus propuestas democratizadoras hacia la sociedad en general; como rasgos negativos, su excesivo carácter local, su debilidad organizativa, y las carencias en sus definiciones programáticas más generales ${ }^{4}$.

\section{EL SURGIMIENTO DE UN NUEVO LIDERAZGO}

El 4 de febrero de 1992 la democracia representativa del Pacto de Punto

\footnotetext{
3. Cfr. López, R. Ob. Cit.

4. Ídem.
} 
Fijo fue sacudida desde sus cimientos. Venezuela quedó al descubierto para sí misma y para el resto del mundo: la democracia burguesa controlada desde 1958 por las élites de los partidos de AD y COPEI, el sindicalismo de empresarios reunidos en Fedecámaras, la burocracia sindical de la CTV, la cúpula de la Iglesia Católica y los altos mandos militares formados en la ideología de la Guerra Fría, dejó a la luz pública las diversas crisis que la postraban. La insurgencia de un grupo de oficiales bolivarianos y nacionalistas abrió un nuevo tiempo histórico que el pueblo supo descifrar. Este grupo de militares, autodenominado $\mathrm{Mo}$ vimiento Bolivariano Revolucionario 200 (MBR-200), encabezado por Hugo Chávez, supo encarnar el descontento popular producido por el Caracazo, además del malestar existente entre la oficialidad media y baja debido a las condiciones socioeconómicas del país, contrastada con la escandalosa corrupción de los altos mandos, el descrédito del liderazgo político tradicional, todo en un contexto de frustraciones generalizadas en los sectores populares y clase media empobrecidas por las agobiantes políticas económicas, por el FMI y el Banco Mundial en beneficio del capital monopolista imperialista.

Esta rebelión militar fracasó en cuanto a su propósito inmediato de derrocar al gobierno de Carlos Andrés Pérez, pero la imagen de Hugo Chávez, su valentía al asumir el movimiento militar golpista, se quedaron para siempre en la conciencia del pueblo venezolano. Había nacido un nuevo liderazgo que las mayorías irán reconociendo. Por paradoja, el revés militar se transformó en un triunfo político. La excarcelación de Chávez en
1994 por sobreseimiento presidencial y su posterior candidatura y triunfo en 1998, colocan en la política nacional y latinoamericana el nacionalismo bolivariano; la unidad cívica militar, la democracia participativa y protagónica, el desarrollo económico endógeno y la integración latinoamericana; orientaciones recogidas en la Constitución de la República Bolivariana de Venezuela de 1999.

La Revolución Bolivariana triunfa con la promesa de convocar una Asamblea Nacional Constituyente para redactar una nueva Constitución, refundar la República y, sobre esta base, derrotar los flagelos de la pobreza, la desigualdad y la exclusión social. Aunque en las elecciones presidenciales de 1998 se escuchan algunos planteamientos en torno al "nuevo socialismo" y al "socialismo del siglo XXI", el discurso electoral de Chávez se concentra en el "poder constituyente". Las primeras ideas de la Revolución Bolivariana se encuentran en los documentos la "Agenda Alternativa Bolivariana" y "Una Revolución Democrática. La propuesta de Hugo Chávez para transformar a Venezuela”. Luego de la primera victoria electoral, estas ideas serán desarrolladas en la Constitución de la República Bolivariana de Venezuela aprobada en consulta popular en 1999 y en los lineamientos del Plan de Desarrollo Nacional 2001-2007. Para entonces, la convocatoria al pueblo radica en impulsar la "democracia participativa y protagónica”.

A partir de la crisis e inestabilidad políticas que comienzan con el Golpe de Estado de 2002, se prolongan con el paro patronal y el sabotaje petrolero y finalmente termina con el Referén- 
dum Revocatorio de 2004, el proceso se radicaliza y aparecen las primeras críticas directas al imperialismo y al capitalismo. Es en el Taller de Alto Nivel de Gobierno, realizado el 12 y 13 de noviembre de 2004 en Caracas, cuando se presenta el "Nuevo Mapa Estratégico", en cuyo contenido se comienzan a perfilar cambios significativos en relación con la orientación de la Revolución Bolivariana.

En el 2006, en las elecciones presidenciales de diciembre, Chávez declara el carácter socialista de la Revolución Bolivariana. Luego de siete años en el poder, Chávez planteó abiertamente la orientación socialista que en adelante le daría a su gobierno y, al calor de la campaña electoral como candidato a la reelección presidencial, el líder de la Revolución Bolivariana planteó claramente que quien vote por Chávez estará votando por el socialismo.

Su abrumador triunfo en las elecciones presidenciales de ese año fue interpretado por un amplio y mayoritario respaldo para concretar la orientación socialista del gobierno; razón por la cual a finales de 2007 se aprueba el Proyecto Nacional Simón Bolívar: Primer Plan Socialista de la Nación. En este documento se plantea los lineamientos generales de las políticas y estrategias que en adelante serán diseñadas y ejecutadas para avanzar en la construcción del socialismo venezolano. A partir de entonces, han proliferado distintas ideas sobre el socialismo bolivariano, el socialismo del siglo XXI y la construcción del socialismo en Venezuela; más como un intento por identificar las aspiración del pueblo venezolano de construir una sociedad libre de desempleo, pobreza y exclusión social, sin que se pueda hablar aún de una doctrina filosófica política sobre el socialismo venezolano, claramente definida y totalmente elaborada ${ }^{5}$. A la construcción del ideario revolucionario bolivariano han contribuido J. R. Núñez Tenorio (1933-1998) $)^{6}$, Hector Mujica (19272002), Carmen Bohórquez (1946), Vladimir Acosta, Rigoberto Lanz (1944), Carlos Lanz (1948), entre otros.

\section{LAS FILOSOFÍAS FEMINISTAS}

Hoy cuando se debaten en América Latina y en el mundo opciones emancipatorias, vías anticapitalistas, condiciones para el buen vivir y la construcción del socialismo del siglo $\mathrm{XXI}$, en Venezuela se hace énfasis a la crítica del patriarcado como una de las estructuras culturales que sostiene, alimenta y reproduce el sistema de explotación de los pueblos. Destacan en esta tendencia, la obra de Gloria Comesaña desde una perspectiva existencialista y la de las intelectuales Iraida Vargas Arena y Alba Carosio, quienes fundamentan sus reflexiones en el principio de que sin feminismo no hay socialismo.

Gloria M. Comesaña S. (1946) es reconocida como una de las principales figuras de la filosofía feminista venezolana. El feminismo existencial es su punto de partida, considerando

5. Cfr. Álvarez, Víctor (2010). Del Estado burocrático al Estado Comunal. Caracas: Editorial Centro Internacional Miranda.

6 Entre su abundante obra destacan: Política, Dependencia y neocolonialismo. Caracas: Ediciones Cabimas, 1971. Marx y la Economía Política. Caracas: UCV, 1969. Teoría y Método de la economía política Marxista. Caracas: UCV, 1979. Sobre Vanguardias y Revolución Socialista. Caracas: Ediciones Cabimas, 1980. 
a la mujer como la construcción social y cultural que ha producido el orden patriarcal. Para Comesaña, la mujer es una "situación" que hay que cambiar porque en ella se refleja la opresión y la alienación a la que se ve condenada la parte no masculina del género humano. Decir mujer en este horizonte es, hablar de un ser diseñado por y para el otro, el varón, que ha usado su poder masculino para anular en la mujer su capacidad de ser sujeto. De aquí que para ella, la condición femenina se inscribe dentro del proceso humano de la alteridad. La situación de sometimiento de la mujer, dentro del orden patriarcal, se explica debido al hecho de que el hombre, basándose en la diferencia femenina, piensa a la mujer como otro. Es más, para el hombre la mujer simboliza la alteridad radical que él, de hecho, no necesita para afirmarse a sí mismo ${ }^{7}$.

Sus obras Mujer, poder y violencia (1991) y Filosofía, feminismo y cambio social (1995) representan su contribución por fundar filosóficamente las reivindicaciones del movimiento feminista sobre las bases de una filosofía existencial que permita a su vez repensar la relación entre la cuestión de la liberación de la mujer y el marxismo tradicional.

Iraida Vargas Arena: La historia como futuro (1999), El agua y el poder (2002), Historia, mujer y mujeres (2006), Resistencia y participación (2007), Feminismo y socialismo (2010), destacan como sus obras fundamentales en las que desarrolla sus

7. Fornet Betancourt, Raúl (2009). Mujer y filosofía en el pensamiento iberoamericano. España: Editorial Anthropos. tesis sobre el feminismo y socialismo del siglo XXI en Venezuela.

Es incuestionable que la vida diaria de las mujeres dentro del capitalismo está alienada y cosificada. Su trabajo, así como la diversidad de sus vidas han sido ignorados y suprimidos mediante mecanismos ideológicos que han hecho posible que muchas de esas vidas sean invisibles. En tal sentido, Vargas Arena, afirma que los modos de pensar y actuar capitalistas han estimulado y legitimado el sistema patriarcal reproduciendo la dominación y los privilegios masculinos. Para ella, las instituciones capitalistas son androcéntricas, por tanto hostiles a las mujeres $\mathrm{y}$, por consiguiente, limitan e inhiben el potencial que tienen las mujeres para la construcción social; por lo que todo proyecto emancipador debe ser feminista. En esta perspectiva, reconoce los avances que en esta materia se han gestado a raíz de la Revolución Bolivariana, donde es indudable la participación activa de la mujer venezolana y el reconocimiento de su potencial transformador ${ }^{8}$.

Alba Carosio: su propuesta feminista se encuentra recogida fundamentalmente en sus obras: Feminismo latinoamericano: imperativo para la emancipación (2009), Frente a la crisis económica y civilizatoria: un nuevo contrato social y feminista (2010), Feminismo y socialismo (2010). En estos textos devela la participación protagónica de las mujeres en la historia latinoamericana, quienes hasta ahora han sido invisibilizadas por la historiografía patriarcal, que ha ocultado el rostro femenino de las luchas sociales. Para

8. Carosio, Alba y Vargas, Iraida (2010). Feminismo y socialismo. Caracas: Editorial El perro y la Rana. 
ella, el socialismo del siglo XXI ha de ser feminista, y por ende, contener un nuevo pacto social, basado en la equidad y en la igualdad, que pone la vida de su sostenibilidad y su reproducción en el centro de la organización socioeconómica, destronando la hoy dominante lógica del beneficio y haciendo responsable el mantenimiento de la vida al conjunto social.

\section{VENEZUELA: EPICENTRO DEL PENSAMIENTO CRÍTICO LATINOAMERICANO}

El proceso de transformación social, política, económica y cultural iniciado por la revolución bolivariana en 1998 dejó al descubierto la necesidad de revisar, reconstruir y proponer categorías y conceptos que permitieran la sistematización de la experiencia emancipatoria del pueblo venezolano. Urgente necesidad impuesta, entre otras razones, por el hecho de que la intelectualidad nacional formada fundamentalmente en la tradición occidental de la modernidad y a la sombra de las grandes figuras del pensamiento europeo, poco o nada tenían que aportar a la nueva realidad en construcción. Como era de esperar muchos de estos intelectuales se convirtieron en profetas del desastre y cruzaron el umbral hacia la derecha endógena. Era el tiempo de crear; en este sentido el Estado venezolano a través del Ministerio del Poder Popular para la Cultura inicia la tarea de impulsar magnas jornadas de debate desde la perspectiva del pensamiento crítico. Para ello instaura el Foro Internacional de Filosofía de Venezuela y el Premio Libertador al Pensamiento Crítico.
A partir de 2005 -año en el que se declara el carácter socialista de la revolución- se da inicio a esas dos instancias con el propósito de reflexionar, discutir y repensar el socialismo frente a los retos que impone el siglo $\mathrm{XXI}$ y las nuevas experiencias emancipatorias que comienzan a multiplicarse en la periferia del sistema, para lo cual se hace necesario resignificar las categorías de Estado, democracia, autonomía, soberanía, libertad, justicia, ideología, solidaridad, identidad, sociedad, derechos humanos, civilización, desarrollo y otras.

A la fecha se han desarrollado cinco ediciones del Foro, con la participación de insignes teóricos del pensamiento crítico $^{9}$, los cuales ajustados

9. Entre los intelectuales internacionales que participaron en estos Foros ubicamos a: Albertine Tshibilondi, Alfonso Sastre, Ana Esther Ceseña; Antonio Scocozza, Arturo Roig, Beat Dietschy, Domenico Lervolino, Enrique Dussel, Enrique Ubieta, Estela Fernández, Eva Forest, Francisco Berdichevshy, Franz Hinkelammert, Gianni Vattimo, Guiseppe Cacciotore, Gustavo Tabares, Horacio Cerutti, Isabel Monal, Joseph Comblin, Juan Manuel Negrete, Justo Soto, Lidia Procesi, Manuel Rodríguez, Marc Blanchard, Mario Sáenz, Pablo Guadarrama, Pierre Mouterde, Rafael Ballén, Albert Kasanda, Carlos Delgado, Carlos Fernández, Darío Salinas, Félix Valdés, Fernando Martínez, Francesca Gargallo, Francisco Beltrán, Georgina Alfonso, Gilberto Valdés, Yohanka León, Hugo Biagini, Jason Garner, Luis Alegre Zahonero, Ricardo Melgar, Sirio López, Atilio Borón, Theotonio Dos Santos, Mely González, Gabriel Vargas Lozano, Fernando Buen Abad, Santiago Alba Rico, Diego Jaramillo, entre otros, y los nacionales: Carmen Bohórquez, Lino Morán, Johan Méndez Reyes, René Arias, Alba Carosio, Carlos Suárez, Daniel Hernández, Francisco Sesto, Gustavo Fernández, José Luis Pacheco, Juan Carlos Silva, Juan José Hernández, Judith Valencia, Luigi Lobig, Luis Damiani, Manuel Mariñas, María Isabel Maldonado, Nelson Guzmán, Alejandro García, Carmen Rivero, Carmen Vallarino, Daniel Castro, Edmundo Aray, Edgardo Lander, Gustavo Borges, Janet Sucre, Jessica Vargas, Juan Pablo Rossel, Luis Brito García, Marta Cecilia Santos, Miguel Ángel Baloa, Nelly Nieves, Obed Vizcaino, Pedro Bracho, Rigoberto Lanz, Roberto Hernández Montoya, Sandra Lozano, Vladimir Acosta, Vladimir Lazo, José Javier León, entre otros. 
a una temática previamente acordada han reflexionado sobre: Capitalismo versus Socialismo. La reposición del debate; Relaciones de poder mundial y paradigmas emancipatorios en el siglo XXI; La defensa de la Humanidad y la construcción colectiva de futuros alternativos: ¿un nuevo socialismo para una nueva realidad?; Nuevas relaciones entre filosofía y procesos políticos; Globalización de la dominación y globalidad de la resistencia; Estados periféricos, burocracias privadas y Estado Imperial; Globalización neoliberal y conflictos interestatales; Construcción del nuevo Estado y sentido de la organización social. La democracia participativa y protagónica como proyecto político alternativo; Descentralización, reorganización, corresponsabilidad y construcción del poder local como fundamentos de un nuevo Estado; Los enemigos de un Estado nuevo: burocratismo, corrupción y desnacionalización; Democracia, interculturalidad y derechos humanos; Conocimiento, comunicación derecho y poder en el mundo actual. Realidad y alternativas; La comunidad de los pueblos en América Latina, Significado y proyección de la Declaración de Cuzco; Los retos de la filosofía en la era del terror imperial; la noción de la humanidad en la era del terror; Pobreza, empoderamiento e instituciones; Sujeto reprimido o sujeto liberado: ley, orden y resistencia popular; Humanismo, revolución y socialismo: hacia un socialismo de cultura humanizadora; Revalorización de la historia del humanismo; Humanismo, reformismo o revolución; Socialismo y cultura frente a la alienación capitalista, La historia como instrumento de liberación transformadora de la sociedad; Utopía y revolución desde el movimiento social popular.

En las declaraciones finales de los foros son muchos los aportes que se recogen de las largas jornadas de discusión entre los intelectuales participantes y de sus comparecencias ante los movimientos sociales de las barriadas, universidades, fábricas e instancias gubernamentales. En líneas generales esta iniciativa recoge el compromiso con una práctica de la filosofía, entendida como instrumento racional de análisis integral de la realidad histórica, con el objetivo de contribuir a su mejor comprensión y transformación, lo que exige la integración orgánica de los intelectuales con los sectores sociales que organizan su resistencia en contra de la dominación y desarrollo, con ello de un pensamiento creador auténticamente revolucionario, el cual tiene que nutrirse de dos fuentes: la del saber acumulado por la humanidad a lo largo de la historia y las experiencias populares que lo legitiman, cuestionan y renuevan ${ }^{\mathbf{1 0}}$.

Se ha tenido presente que el proyecto de dominación imperial, de carácter planetario, constituye la principal amenaza para la soberanía de nuestros pueblos; que los gobiernos democráticos, junto a la resistencia popular, constituyen las trincheras en las que se está jugando hoy el destino de la humanidad y que junto con otras iniciativas y propuestas gubernamentales democráticas, Venezuela, en su itinerario de revolución bolivariana, viene estableciendo un significativo referente de resistencia y de voluntad política por consolidar un proyecto autónomo

10. “Declaración del I Foro Internacional de Filosofía de Venezuela" 10 de julio de 2005 (2006). En: Memorias del I Foro Internacional de Filosofía de Venezuela. Caracas: Ministerio de la Cultura. 
de cara al mundo y con capacidad de autodeterminación ${ }^{11}$.

Frente a un sistema capitalista que se caracteriza por la explotación del hombre por el hombre, por el saqueo de los recursos naturales, la desestructuración de las culturas indígenas, la destrucción de la vida y la alienación, no hay terceras vías. Según se recoge en la declaración final del III Foro Internacional de Filosofía de Venezuela "Solo el socialismo es la supresión y la superación del capitalismo". El socialismo del siglo XXI tiene la tarea de recuperar y valorar las innegables conquistas de los socialismos del siglo XX, pero al mismo tiempo tiene que superar sus deficiencias y contradicciones como el excesivo énfasis en el "desarrollo" económico, el Estado degenerado en burocratismo, el menosprecio de la diversidad y el olvido de la naturaleza ${ }^{12}$.

En el marco del IV Foro Internacional de Filosofía de Venezuela se afirma que la interpretación filosófica sólo es transformadora si surge y se enmarca en procesos revolucionarios emancipatorios, lo que obliga a incluir la diversidad de saberes y perspectivas epistemológicas comprometidas con el ser humano y la vida. Tarea que se hace urgente y necesaria en momentos en los que el capitalismo, en su fase imperialista, ha fracasado como orden económico y civilizatorio. Todo esto hace imperativo elaborar una teoría socialista del consumo que ajuste las necesidades a los límites materiales del planeta, garantizando reciprocidad

11. "Declaración del II Foro Internacional de Filosofía de Venezuela" 10 de julio de 2006 (2007). En: Memorias del II Foro Internacional de Filosofía de Venezuela. Caracas: Ministerio de la Cultura.

12. "Declaración del III Foro Internacional de Filosofía de Venezuela" noviembre 2007 (2008). En: Memorias del III Foro Internacional de Filosofía de Venezuela. Ministerio de la Cultura. Caracas. entre humanidad y naturaleza, y asegure la construcción de nuevos sujetos políticos, éticos, eróticos, pedagógicos y estéticos, capaces de generar y conservar y orden social justo y humano ${ }^{13}$.

Esta experiencia de convocar a los intelectuales con el propósito de acompañar los procesos emancipatorios, constituye una experiencia inédita en el contexto venezolano y latinoamericano, si se tiene en cuenta que ha sido el Estado venezolano el que lo ha propiciado al estar consciente de la necesidad de elaborar nuevas teorías. La necesidad de pensar el hecho filosófico en su relación con el tiempo histórico como una filosofía crítica y emancipadora que, además de analizar y comprender la naturaleza de los conflictos, contribuya a construir las políticas estratégicas capaces de poner en marcha prácticas antihegemónicas con el objetivo primordial de garantizar la plena realización de la condición humana ${ }^{14}$.

Sumado a ese esfuerzo gubernamental, el Estado venezolano viene propiciando el Premio Libertador al Pensamiento Crítico ${ }^{15}$, lo que constitu-

13. “Declaración del IV Foro Internacional de Filosofía de Venezuela" 2008 (2009). En: Memorias del IV Foro Internacional de Filosofía de Venezuela. Caracas: Ministerio de la Cultura.

14. "Declaración del V Foro Internacional de Filosofía de Venezuela" 14 de julio de 2010. En: Memorias del V Foro Internacional de Filosofía de Venezuela. Caracas: Ministerio de la Cultura.

15. Entre los galardonados de este premio destaca: Franz Hinkelammert con su obra El Sujeto y la Ley. El retorno del sujeto reprimido (2005); Bolívar Echeverría con su obra: Vuelta de siglo (2006); Renán Vega Cantor con su obra: Un mundo incierto, un mundo para aprender y enseñar. Las transformaciones mundiales $y$ su incidencia en la enseñanza de las Ciencias Sociales (2007); István Mészáros con su obra: El desafío y la carga del tiempo histórico. El socialismo del siglo XXI (2008); Enrique Dussel con su obra: Política de la liberación. Volumen II. Arquitectónica (2009). Carlos Fernández y Luis Alegre con su obra: El orden de El Capital (2010). 
ye un reconocimiento a la labor reflexiva de autores que han desarrollado una labor distinta a la mirada monolítica del pensamiento único. Procura ser un tributo a la capacidad de generar ideas heterodoxas, fundando nuevas plataformas para el debate y la discusión de la realidad contemporánea, reflexiones críticas alternativas comprometidas con el presente y el futuro de la humanidad.

Los acontecimientos del Caracazo de 1989 y el inicio de la Revolución Bolivariana de 1999, constituyen dos hitos de la historia reciente venezola- na que sin lugar a dudas han tenido su impronta en el desarrollo del debate filosófico nacional actual. El protagonismo popular y la concreción de un modelo político que obedezca a los anhelos de las grandes mayorías han sido preocupación evidente en la intelectualidad. Ciertamente la polémica ha colmado los espacios universitarios, pero más allá de estos, la experiencia venezolana se ha constituido en epicentro de un gran debate continental dado que la propuesta de la construcción del socialismo del siglo XXI es tarea que apenas comienza.

\section{BIBLIOGRAFÍA}

Álvarez, Víctor (2010). Del Estado burocrático al Estado Comunal. Caracas: Editorial Centro Internacional Miranda.

Corosio, Alba y Vargas, Iraida (2010). Feminismo y socialismo. Caracas: Editorial El perro y la Rana.

Fornet Betancourt, Raúl (2009). Mujery filosofía en el pensamiento iberoamericano. España: Editorial Anthropos.

López, Roberto (2009). El protagonismo popular en la historia de Venezuela. Maracaibo: Editorial Escuela de Formación Popular Nuestra América.

Memorias del I Foro Internacional de Filosofía de Venezuela (2006). Caracas: Ministerio de la Cultura.

Sosa, Arturo y González, Wilfredo (2008). "Desarrollo histórico del proceso político venezolano del siglo XX” En: Una mirada sobre Venezuela. Caracas: Editorial Centro Gumilla. 